$\xi=1$

\title{
The impact of simulation practice on student nurses' skills: the case of integrated newborn and childhood illness management at the university of Namibia
}

\author{
Hermine Iita $^{1 *}$, Hanna Neshuku ${ }^{2}$, Moses Chirimbana ${ }^{3}$ \\ ${ }^{1,2}$ Lecturer for Community Health Nursing Faculty of Health Sciences School of Nursing Public Health Department \\ University of Namibia, Oshakati Campus \\ ${ }^{3}$ Lecturer for Mathematics and Statistics Science Foundation Programme University of Namibia, Oshakati Campus \\ *Corresponding author E-mail: hiita@unam.na
}

\begin{abstract}
The purpose of this study was to determine if guided simulation practice could enhance practical skills of student nurses in management of childhood illnesses, based on the Integrated Management of Newborn and Childhood Illness (IMNCI) approach.

The objective was to determine the level at which guided classroom simulation practice enhances the skills of student nurses regarding assessment and classification of sick children aged two months to five years for treatment. A quantitative research approach using a pretest and post- test strategy was used. Descriptive statistics were done and a t-test was also performed to determine the difference in the means. Findings demonstrate that there is an improvement in the performance of student nurses as a result of the guided classroom simulation practice. Recommendations include that student nurses be exposed to guided simulation practice before they are deployed in the clinical area for the actual assessment and classification of sick children based on the Integrated Management of Neonatal and Childhood Illness.
\end{abstract}

Keywords: Integrated Management of Neonatal and Childhood Illness (IMNCI) Approach; Simulation; Student Nurses.

\section{Introduction}

Current research findings indicate that there is a great need for high education institutions, as well as similar institutions involved in mentoring practitioners, to develop a culture of real world experiences in classroom and laboratory settings in order to allow students and practitioners to apply the theory learnt before they implement it with real life subjects. By doing so, a student or practitioner is provided with an opportunity to develop confidence in transferring the skills learnt into reality within a safe environment, and without real life pressures, in order to gain confidence in performing the practical skills expected of professionals in their field This act of creating simulated real world experiences is discussed by Irvine \& Martin (2014) and O'Neil, Huntley-More \& Race (2007), where they mention that clinical simulations are effective in increasing preparedness for practice among students of nursing and other health care related education. Irvine \& Martin (2014) specifically pointed out that with simulation, the theory -practice gap is minimized.

In health care related education, including nursing education, simulation-based education (SBE) provides an educator with the opportunity to dissect clinical skills into smaller and more manageable sections such that students could be presented with scenarios and tasks that fit their stage of learning, thus reducing the cognitive load the student has to face within real case management situations (van Merriënboer \& Sweller, 2005).

Integrated Management of Newborn and Childhood Illness (IMNCI), is a strategy developed by the World Health Organization (WHO) and the United Nations Children's Fund (UNICEF) to address morbidity and mortality in children under five years worldwide. Many countries including Namibia, have adopted this approach in their health care delivery systems. The Ministry of Health and Social Services (MOHSS) in Namibia adopted this approach in the year 2000(UNAM, 2010).

This innovative method of providing child health care delivery focuses on treating the whole child, rather than concentrating on a single disease or condition.

It simultaneously targets the management of multiple disease symptoms including difficulty breathing, diarrhea, fever, sore throat, ear problems, malnutrition and anemia, suspected symptomatic HIV infection as well as any other problems the child might be experiencing that the caretaker may not be aware of. With this approach, the immunization and Vitamin A supplementation status of each child is also checked and attended to. Initially, this approach was called Integrated Management of Childhood Illness (IMCI) though later on this theme was changed to Integrated Management of Newborn and Childhood Illness (IMNCI) in order cater to the health care needs of the newborn babies (WHO, UNICEF \& MOHSS, 2010).

According to a study done in Tanzania, which aimed to assess the effect of Integrated Management of Childhood Illness (IMCI) relative to routine care on the quality and efficiency of providing care for sick children in first-level health facilities, IMCI training is associated with significantly better child health care in facilities at no additional cost to districts. (Bryce, Gouws, Adam , Black, Schellenberg, Manzi, Victora \& Habicht, 2005).

The University of Namibia (UNAM) introduced this approach into its nursing education curriculum in 2003, in order to respond to the health care needs of the country (UNAM, 2010). For the first 
seven years, a block system was used to teach this approach Workshops were conducted for the final year student nurses and included teaching the necessary skills, as well assessing their performance against the requirements of this approach. Later on, this approach was integrated into the curriculum, and UNAM lecturers were expected to teach and guide students from their second year through their fourth and final year of study (staggered approach).

In 2013 the lecturers at the University of Namibia, Oshakati Campus carried out this action research to assess how simulation based education could be used in teaching practical skills in IMNCI approach to nursing students. The reason why the researchers choose to study this problem at the Oshakati Campus of the University of Namibia nursing school is because two of the authors are teaching at this campus, and they are trained to teach, assess and to conduct health facility practice follow up and supervision whereby they will oversee whether student nurses and other health care workers who use this approach to treat the sick children are doing it correctly and, to give the necessary support as need be.

Another reason why this study was conducted at Oshakati campus is because student nurses at Oshakati campus to fulfill their qualification requirement they need to undergo pre-service training in the management of sick children based on the IMNCI approach There for this approach was selected aiming at preparing them to be able to treat all children "health problems simultaneously when they are allocated at health facilities for clinical practice.

Although many students perform very well when implementing this approach, some challenges were faced regarding the assessment of these students when they were placed in real health facilities practice. This action research project provided nurse educators with an opportunity to reflect on their own practices while improving student learning (Creswell, 2008).

\section{Problem statement}

The problem faced before this action research project evolved when the block system of class scheduling was eliminated; creating a greater need for teaching and coordination of practice in IMNCI during their regular theoretical and practical sessions. Although many students were evaluated and found that they mastered the necessary clinical skills for treating children using this IMNCI approach during their second and third year of training, their final evaluation(in their fourth year] proved problematic as some of the student nurses were not prepared to initiate IMNCI procedures within a clinical setting. While at practice some students did not possess the necessary manuals each health worker needed in order to properly treat children using the IMNCI approach.

In some cases, lecturers involved with student nurses' clinical practice used most of their time in teaching and guiding students instead of conducting the required evaluations, as many students were obviously not prepared for assessment in their application of the IMNCI approach.. Hence, plans needed to be put in place to make the assessment of this approach smoother, more beneficial and less expensive in terms of time management for the staff. Moreover, this assessment plan needed to have minimal inconvenience for the patients who were to receive treatment based on IMNCI, and for their caregivers. Unfortunately, the authors' observed, and were concerned with the lack of proper coordination for this clinical activity.

The section that follows deals with literature review about simulation-based training and how it could be applied in IMNCI approach to child treatment.

\section{Literature review}

Simulation-based education (SBE) attempts to create characteristics of the real world for students and practitioners to enhance the transferability of their skills to the real setting and it can be used in a variety of teaching and learning situations ranging from using computers to simulate mathematical data or weather conditions to human patient case management situations(van Merriënboer \& Sweller, 2005).

Throughout the world, SBE is being encouraged. For example, in Australia the body called Health Workforce Australia is driving initiatives to develop a more coordinated national approach to optimize the benefits of simulation in educational settings. However, for SBE to be effective there needs to be a structure in place which can enable the school to optimize the timing of SBE interventions. This is necessary in order to meet the learners' needs while providing opportunities for repeated practice with feedback, structured learner reflections to broaden the application of SBE to clinical experiences, and the maintenance of close working relationships between clinicians, educators and simulation technicians during the development of SBE programs (Irvine \& Martin, 2014). In the United States, one study by Young \& Burke (2010) evaluated a pilot residency program for new graduate nurses and doctors of pharmacy that used patient simulations. The eight-week orientation program included a review of policies and procedures, small group discussions and practice laboratory simulations with two static mannequins who had cardiac monitoring capability or heart, lung and bowel sounds. The researchers used two instruments to obtain quantitative and qualitative data from the participants. Overwhelmingly, participants reported that the program, especially the simulations, helped better prepare them to practice independently in the hospital. More than $50 \%$ of participants ranked simulations the highest in helping to develop hands-on skills. Also, $70 \%$ felt that the program presented helpful information that was not covered in one-on-one care for real patients under their preceptor's guidance. Participants not only rated simulations as their favorite part of the course, but they also felt that simulations contributed the most to learning. In addition to developing the participants' clinical practice, simulations also helped them gain resource utilization skills, policy and procedure awareness, and a sense of camaraderie with their co-workers.

In another study done in Jordan by Hadid and Suleiman (2012), the researchers, who were nurse educators, measured the effect of an additional training sessions supported by simulation on the retention of cardiopulmonary resuscitation (CPR) knowledge and skills in 40 nursing students. Participants completed a pre-test, attended a 3-hour CPR workshop, and completed a post-test. The experimental group attended simulation-supported boost training during week six. is study's findings indicated that the experimental group achieved significantly more improvement in CPR procedures than the control group in the post-test. Clearly, simulation-based education (SBE) is a rapidly developing discipline that can provide safe and effective learning environments for students. Moreover, clinical situations for teaching and learning purposes are created by using mannequins, part-task trainers, simulated patients or computer-generated simulations (Ziv, Wolpe, Small \& Glick , 2003; Weller, 2004).

A major challenge with teaching and learning in clinical settings is that it is opportunistic and unstructured. This can be overwhelming for students who are often required to attempt tasks for which they are ill-prepared. SBE allows deconstruction of clinical skills into their component parts so students can be presented with scenarios and tasks appropriate for their stage of learning, thus reducing cognitive overload. Without the complexities of dealing with real patients, students can focus on mastering basic skills and can more readily learn the principles from their experiences to apply in other settings (van Merriënboer \& Sweller, 2005).

SBE encompasses a wide spectrum of techniques and there is a growing body of research supporting its value in medical school education. Moreover, SBE needs to be integrated into medical curricula at the developmental stage, with careful attention paid to the transfer of skills learnt to the real clinical environment. It is crucial that SBE programs are evaluated for their impact on student and patient outcomes. The use of SBE will continue to expand with the evolution of new technologies, but well developed policies are required to ensure coordinated and cost-effective approaches to its wider implementation (Ackerman, 2009). 
The primary beneficiary of assessment should be the student. To achieve this in the assessment context, students and lecturers must engage in a process of dialogue and feedback regarding the students learning progress. Moreover, students need be given time to analyze the feedback and to find a way to improve their performance. Emphasis must also be given to formative assessments as they provide students with the chance to reflect on the gap between their current level of understanding/knowledge and the desired cognitive goals. (Hatzipanagos \& Rochon, 2012).

Based on this literature review, the researchers were convinced of the importance of simulation-based education (SBE). Thus, this study will now explore the ways in which SBE can be used effectively when implementing the IMNCI approach. In this way, student nurses will gain the experience necessary to be more confident in future clinical situations where they will be treating real patients.

\section{Purpose and objectives of the study}

The purpose of this study was to determine if guided simulation would enhance the skills of student nurses when they implement the Intergraded Management of Neonatal and Childhood Illness (IMNCI) approach. The objective of the study was to determine the level at which guided classroom simulation practice enhances the skills of student nurses regarding assessment, classification and treatment of sick children. To this end, a null-hypothesis and alternative hypotheses were developed as follow:

Null Hypothesis $\left(\mathrm{H}_{\mathrm{o}}\right):=0$ (There is no mean improvement as a result of the simulation).

Alternative Hypothesis $\left(\mathrm{H}_{\mathrm{a}}\right)$ : $>0$ (There is mean improvement as a result of the simulation).

\section{The study context}

This study was conducted during the second semester of the fourth year of study. The student nurses had already been introduced to this approach during the previous two years of study, and had covered the introduction to the IMNCI approach, assessment of general danger signs, as well as assessment of the main symptoms which include coughing and difficult breathing, fever, diarrhea, ear problems, sore throat, malnutrition, anemia and HIV infection. They were also taught how to classify the child illness based on this assessment information and how to identify the correct treatment for the child which are also the component of the approach At this level emphasis should be placed on ensuring that the student nurses are able to treat the child correctly by linking their experiences with the content that was taught the previous years.

\section{Study design and methods}

This study used mixed methods which included a quantitative approach with a pre-test and post-test designed to measure student performance. In addition, an open ended questionnaire was administered to students to determine how they perceived the guided simulation practice and tests, the study's population comprised of 79 student nurses in their third year of education who were registered in the Community Health Nursing Science course at the Oshakati Campus of the University of Namibia. The Oshakati Campus is situated in a remote area where nurses will be expected to manage cases of childhood illness independently. The Community Health Nursing Science course included instruction in the IMNCI approach.

Probability sampling was used to select those students that were to be included in the study. In this case, the criteria used was that the students should be full time in the theoretical block and be able to attend all simulation classes during the two weeks when this exercise was carried out. A total of thirty-four (34) student nurses met these criteria and were included as study participants.
Data was collected using a special IMNCI assessment form which is normally used for this purpose in a clinical setting. This form includes personal particulars of the patients, whether this is an initial or follow-up visit, and main symptoms and health status such as difficulty breathing, diarrhoea, fever, sore throat, ear problems, malnutrition, anaemia, suspected symptomatic HIV infection, immunizations, vitamin A supplementation status as well as any other problems the child might present at the health facility (whether or not the child's caregiver was aware of these conditions). An open ended questionnaire was also given to students so that they might reflect upon their experiences within this simulation guided practice.

\section{Measure of trustworthiness}

Measure of trustworthiness was assured through: Validity. In this study, the following aspects of validity were adhered to: Face validity, which is concerned with the superficial appearance or face value of the research instrument. In this study the researchers ensured face validity by using an instrument that was already being used in clinical situations throughout Namibia. Content validity, which is concerned with the adequacy of the content area being measured. In this study, content validity was assured as the data collection form had sections that cover all main childhood symptoms to be assessed, classified and treated within this approach (De Vos, Strydom, Fouche \& Delport, 2011; Babbie, 2008).

Reliability: In this study, the research instrument was the one used by health workers in clinical settings within Namibia, and thus the students were already familiar with the instrument from their second year of study. The case data was presented in such a way that students were able to transfer data from the case scenario to the form. A colleague who was an expert in the IMNCI approach was requested to moderate the case to ensure that the student nurses clearly understood the approach and process to be followed. Students then used this data to classify and treat the child. The same case was administered for both pre- and post-test assessment.

No pilot testing of the data collection instrument was done because this was a standard instrument already used in the clinical area. However, a colleague was requested to moderate the case scenario in order to make sure it was user friendly and that students could interpret this instrument correctly.

Research Methods Used in This Study:

1) An initial pre-training assessment (pre-test) was conducted in the classroom for all students before their initial training at the third year level.

2) An initial training session with simulated case data was conducted over a two week period for students at the third year level. Students were given the necessary guidance and allowed time to practice while in the classroom, and later in real clinical practice at the health facility in the health district where they were being trained.

3) A post-training assessment (post-test) was conducted in the classroom for all students after they completed their training with the necessary guidance.

4) Before the final examination, a needs assessment survey using open -ended questions was conducted to determine the learning gaps, as identified by the students.

5) The marks obtained on an initial assessment were compared to a later assessment (pre- and post-test). A comparison was made to determine whether there had been any growth or change in initial scores when compared to later scores

Data Analysis Procedures: Descriptive statistics were obtained indicating mean percentages of students' pre- and post-test results. Inferential statistical analysis of the data was also carried out wherein the mean for the pre-test was compared to the mean for the post-test. A student t-test was used in the data coding of qualitative information obtained through an open-ended survey of students regarding their experiences in this clinical activity.

The researchers in this study adhered to the following requirements to ensure ethical research: 
Confidentiality was assured in this study as the raw data were not shared in any way that may have jeopardised the safety of the participants. Voluntarism was adhered to in this study as each participant was informed that they had the right to refuse to participate in the study and that they had the right to withdraw from the study at any time without fear of coercion. However, they were also informed about the benefit this participation could have on their learning process. Anonymity was maintained in this study, and all participants were assured that the raw data would remain confidential. Freedom from harm for all participants in this study was assured as no one was exposed to either physical tests or treatment.

Informed consent for this study was obtained from all participants without manipulation by the researchers. Moreover, each participant was provided with all the necessary information regarding what the study entails, and each participant was informed that they would be briefed about the outcome of the study upon its completion. Written permission to conduct this study was granted by the University of Namibia Management at Oshakati Campus, and informed consent of all the study's participants was obtained and each was provided with an explanation of the study's purpose, the benefits of the study and the study proceedings before the data collection began. Results were also shared with all study participants.

\section{Results}

All thirty four (34) third year student nurses who participated in this study passed both the pre- and post-test. The average pre-test score was $75 \%$ correct, with a range of $56 \%$ to $90 \%$. The average post-test score was $85 \%$, with a range of $72 \%$ to $96 \%$. There was a need to teach this student nurses again because, the aim with this approach is to have them scoring as higher as possible in order to ensure that when they treat real children, and safety regarding treatment is assured. Figure 1 below gives a graphical presentation of average percentage for the pre and posttest.

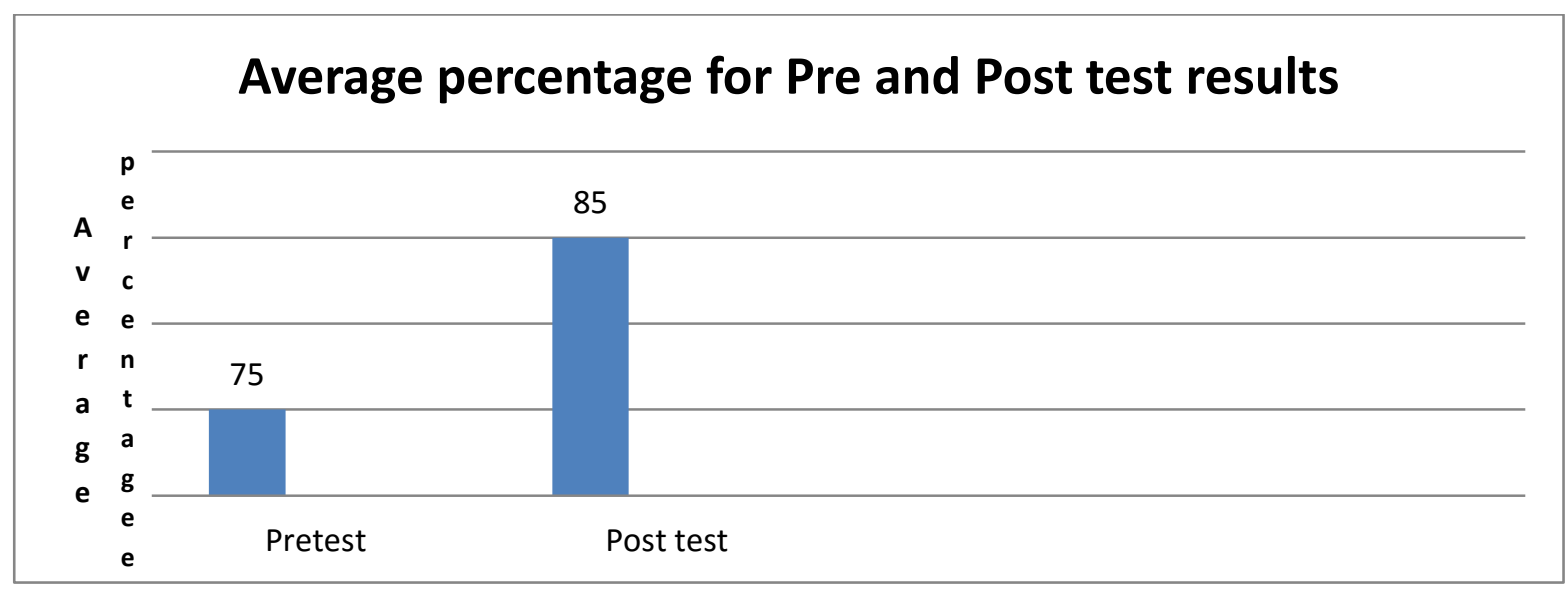

Fig. 1: Graphical Presentation of Pre- and Post- Test Results Average Percentage.

\section{Inferential statistics}

As this study contained only a small sample, a t matched pair hypothesis test was considered most suitable to determine the effectiveness of the rendered treatment (Christensen, John, and Turner, 2010).Table 1 and 2 below summarise the inferential statistical results. A presentation of calculations and results with regard to the t-test follow the two tables.

Table 1: Summary of the Results of the Posttest and the Pretest

\begin{tabular}{lllll}
\hline & N & Mean & Standard Deviation & Sum \\
\hline Pretest & 34 & 75.53125 & 9.24918 & 2417 \\
Posttest & 34 & 85.5625 & 8.43929 & 2738 \\
\hline
\end{tabular}

Table 2: Summary of the Results of Posttest minus Pretest

\begin{tabular}{lllll}
\hline & N & Mean & Standard Deviation $(\mathrm{S})$ & Sum \\
\hline Posttest-Pretest & 34 & 10.40625 & 6.862047917 & 333 \\
\hline
\end{tabular}

$\mathrm{H}_{\mathrm{o}}:=0$ (There is no mean improvement as a result of the treatment).

$\mathrm{H}_{\mathrm{a}}:>0$ (There is mean improvement as a result of the treatment).

$\mathrm{A}=0.05$

$\mu_{\mathrm{d}}=\mu_{\text {posttest }}-\mu_{\text {pretest }}$

$$
\begin{aligned}
{ }^{t_{\text {Calcu }}} & =\frac{-}{\frac{\mathrm{x}-\mu_{\mathrm{d}}}{\sqrt{\mathrm{n}}}} \\
= & \frac{34.2-0}{\frac{6.888467202}{\sqrt{34}}} \\
= & 28.94962
\end{aligned}
$$

Finding t standard

$$
\begin{aligned}
\mathrm{t}_{\mathrm{s} \tan \text { dard }}=\mathrm{t}_{\mathrm{n}-1 ; \alpha} \\
=\mathrm{t}_{34-1 ; 0.05} \\
=\mathrm{t}_{33} ; 0.05 \\
=1.692
\end{aligned}
$$

Decision Rule: Since $\mathrm{t}_{\text {Calculated }}>\mathrm{t}_{\text {Standard: }}$ Reject $\mathrm{H}_{0}$.

Conclusion: There is an improvement in performance as a result of the treatment rendered.

A matched pair $t$ hypothesis test $\left(\mu_{\text {Posttest }}-\mu_{\text {Pretest }}\right)$ showed that $\left(\mathrm{t}_{\text {calculated }}=28.57858 ; \mathrm{t}_{\text {standard }}=1.696 ; \alpha=0.05\right)$ the null hypothesis was rejected in favor of the alternative hypothesis which stated that: There is mean improvement as a result of the treatment.

Summary of feedback by students regarding their experiences during the clinical activity. The results from this study indicate that guided simulation based education is useful, provided that the necessary measures are put in place to support students when they implement classroom theory in real clinical situations. The following quotations underscore this study's results, as well as provide suggestions for making the implementation of IMNCI more successful:

1) "About IMNCI, the lecturers should please at least remind students of what they were taught the previous year, because not all students catch all what they were taught".

2) "We almost forgotten much on IMNCI but now, after your re-enforcements, we can now classify even without using the IMNCI chart booklet, is only that this is not allowed".

3) "The IMNCI materials must also be given together with the practice register early in the year because now we were giv- 
en them too late and some of us were allocated to work in the clinics at mind year, which then became a major problem to us because we had to leave the places where we are allocated to go and complete this practice which is leading to decrease our practical hours for other subjects".

A detailed discussion about the themes of experience of students as reflected here will be presented in a separate follow up paper.

\section{Discussion}

Although all thirty-four (34) students passed the pre-test, we are dealing with the treatment of sick children, with the aim of saving their lives. To this end, we would want all participants to achieve $100 \%$ to ensure that every child treated will return home cured (WHO, UNICEF and MOHSS, 2010).

The post-test results compared to the pre-test results indicate that there was an improvement in the performance after the simulationbased education was implemented with the group.

Moreover, remarks obtained from student evaluations of their clinical exercise indicated that there was great need for the IMNCI approach in nurse education programs, as this simulation-based training can result in safe clinical practice.

\section{Conclusion and recommendations}

Student nurse performance improved as a result of the guided classroom simulation practice, as evidenced in the pre-test and post-test results. It is therefore recommended that student nurses be exposed to regular guided simulation practice before they are deployed in clinical practice. There is also a need to strengthen simulation practice at all levels of training from second year to the fourth year of training to ensure skill integration. It is also recommended that strengthening measures to ensure that every student attend all the theoretical sessions and simulation lessons, and that they have the necessary manuals/charts and booklet for this IMNCI approach. Moreover, simulation should be done under supervision, and afterwards students should be given another chance to practice on real patients under supervision, and not to be declared competent based on simulation cases only.

Additional research should be conducted to determine areas that need improvement when using simulation for the purpose of IMNCI implementation with student nurses. Also, proper coordination of the real clinical practice is needed between the school and the clinical staff. Additional research will also be conducted to determine how students view the simulation guided practice in IMNCI.

\section{Limitations of the study}

This study was conducted using one group only and there was need that it be applied on multiple groups of student nurses to determine if the trend of findings remains similar as situations change.

\section{Acknowledgement}

The authors would like to express their appreciations for the following individuals and institutions:

1) All the lecturers in the Nursing School at Oshakati Campus who were involved in the guidance of student nurses around this time about the IMNCI approach. They are thanked for their contributions in the area of IMNCI clinical follow up.

2) The University of Namibia (UNAM) for transport and technical support.

3) The Ministry of Health and Social Services (MoHSS) in Namibia, for practice

4) Space in health facilities and for technical the support provided.
5) An international Scholar who was that time at the University of Namibia and she assisted us in the final shaping of this manuscript. She is: Professor Karen Biraimah, Ph.D. Fulbright Scholar, Namibia, 2015 Professor and Director International and Special Programs. College of Education and Human Performance, ED 209H.University of Central Florida. Orlando, Florida 32816-1250.USA.

\section{References}

[1] Ackerman, A. D. (2009) Investigation of learning outcomes for the acquisition and retention of CPR knowledge and skills learned with the use of high-fidelity simulation. Clinical Simulation in Nursing. 2009, 5(6): e213-e222. http://dx.doi.org/10.1016/j.ecns.2009.05.002.

[2] Babbie, E. (2008). The basics of social research (4th ed.). Canada: Thomson Wadsworth.

[3] Bryce, J., Gouws, E., Adams, J., Black, R. E., Schellenberg, J. A., Manzi, F., Victora, C. G., \& Habicht, J-P. (2005). Improving quality and efficiency of facility-based child health care through integrated management of childhood illness in Tanzania. Oxford, UK: Oxford University Press in association with The London School of Hygiene and Tropical Medicine.

[4] Christensen, L.B; John, B.R. \& Turner, A. L. (2010). Rsearch methods, design and analysis. Boston: Courier Companies.

[5] Creswell, J.W. (2008). Educational Research. Planning, Conducting, and Evaluating Quantitative and Qualitative Research. (3rd Ed.). New Jersey: Pearson.

[6] De Vos, A. S., Strydom, H., Fouche, C. B., \& Delport, C. S. L. (2011). Research at grass roots: For the social sciences and human service professions (4th ed.). Pretoria, South Africa: Van Schaik.

[7] Hadid, L. A. \& Suleiman, K.H. (2012). Effect of Boost Simulated Session on CPR Competency among Nursing Students: A Pilot Study. Journal of Education and Practice.Vol 3, No 16, 2012.

[8] Hatzipanagos, S. \& Rochon, R. (2012). Approaches to Assessment that enhance learning in higher education. London: Routledge. Volume 35 , issue 5 .

[9] O’Neil, G., Huntley-More, S. \& Race, P. (2007). Case Studies of Good Practice in Assessment of Student Learning in Higher Education. Dublin: AISHE. Retrieved from URL:http://www.aishe.org/readings/2007-

/http://www.webopedia.com/TERM/S/simulation.html; Irvine, S and Martin, J. (2014), Bridging the gap: from simulation to clinical practice. The Clinical Teacher, 11: 94-98. http://dx.doi.org/10.1111/tct.12060.

[10] UNAM (2010). IMNCI: Integrated Management of Newborn and Childhood Illness Pre-Service Training Handbook. (3rd Ed.). Windhoek: Hierogglyphics Advertising Agency.

[11] Van Merriënboer J, Sweller, J. (2005) Cognitive load theory and complex learning: recent developments and future directions. Educ Psychol Rev 2005; 17: 147-177. http://dx.doi.org/10.1007/s10648005-3951-0.

[12] Wagenaar, E., \& Babbie, E. (2008). The basics of social research:Study guide. Belmont, United States of America: Thomson Wadsworth.

[13] Weller, J. (2004) Simulation in undergraduate medical education: bridging the gap between theory and practice. Med Educ 2004; 38 32-38. http://dx.doi.org/10.1111/j.1365-2923.2004.01739.x.

[14] WHO, UNICEF \& MOHSS (2010). Integrated Management of Newborn and Childhood Illness.Geneva: World Health Organization.

[15] Young, P., \& Burke, J. (2010). Evaluation of a multidisciplinary, simulation-based hospital residency program. Clinical Simulation in Nursing. 2010, 6(2): e45-e52 http://dx.doi.org/10.1016/j.ecns.2009.08.005.

[16] Ziv A., Wolpe P., Small S \& Glick S. (2003). Simulation-based medical education: an ethical imperative. Acad Med 2003; 78: 783788. http://dx.doi.org/10.1097/00001888-200308000-00006 